Original Research Article

\title{
Knowledge, attitude and practices about antimicrobial resistance and appropriate use of antimicrobial agents among the MBBS students of a medical college hospital in Eastern India
}

\author{
Abhishek Ghosh ${ }^{1 *}$, Snehasish Das ${ }^{2}$, Raju Dasgupta ${ }^{3}$
}

\begin{abstract}
${ }^{1}$ Department of Pharmacology, ${ }^{2}$ MBBS student, ${ }^{3}$ Department of Community Medicine, College of Medicine and JNM Hospital, Kalyani, West Bengal, India
\end{abstract}

Received: 31 January 2018 Accepted: 05 February 2018

\section{*Correspondence to: \\ Dr. Abhishek Ghosh, \\ Email: drghosh.new@ gmail.com}

Copyright: () the author(s), publisher and licensee Medip Academy. This is an openaccess article distributed under the terms of the Creative Commons Attribution NonCommercial License, which permits unrestricted noncommercial use, distribution, and reproduction in any medium, provided the original work is properly cited.

\begin{abstract}
Background: Antimicrobial agents are one of the most commonly used as well as misused drugs. Rational antibiotic use is thought to be the best way to control resistance. Awareness and practice about antimicrobial use and resistance among medical students of different years so that appropriate measures can be taken to educate them properly to prevent misuse of antimicrobial as far as possible.

Methods: It was a cross sectional questionnaire-based study undertaken in a teaching hospital in Eastern India among 328 medical students in 4 different batches. their responses remained confidential. total correct and incorrect responses from each of the 4 batches of MBBS students. overall trend and batch wise difference in the responses were analyzed.

Results: Most of them had idea about problem of antimicrobial resistance and most of the students answered majority of the questions correctly. While assessing difference in responses in different batches, result showed that there was very significant improvement in the response of 6th semester students than the response of 4th semester students, may be due to acquiring knowledge of antimicrobials from their pharmacology classes in that period.

Conclusions: Overall knowledge of antimicrobial resistance and proper use of antimicrobials appears good among different batches of MBBS student of this institution, though some areas need to be improved. Knowledge improvement is most evident from 4th semester to 6th semester students. Pharmacology training appears to make students more aware of this problem. Regular education is important to make them more aware.
\end{abstract}

Keywords: Antimicrobial resistance, Attitude, Knowledge, MBBS students, Practice

\section{INTRODUCTION}

Antimicrobial agents are one of the most commonly used as well as misused drugs. ${ }^{1}$ They were viewed as magical bullets when first came into clinical practice. However soon after the discovery of penicillin, resistance developed quickly. Bacteria produced resistance against almost each new antimicrobial agent. This is mostly aided by irrational as well as indiscriminate use of antibiotics. ${ }^{2}$ Overprescribing is driven largely by diagnostic uncertainty, patient demand and time pressure on clinicians. Rational antibiotic use is thought to be the best way to control resistance. Inappropriate and irrational use of medicine provides favourable conditions for resistant microorganisms to emerge and spread.

Irrational use of antibiotics also involves self-medication. It is estimated that more than $50 \%$ of antibiotics worldwide are purchased without prescription. ${ }^{3}$ Patient factors relating to incorrect antibiotic use include self-medication, not taking a full course of treatment and taking the course for another occasion. ${ }^{4}$ 
In India any antibiotic, including higher-end ones, can be purchased over the counter without prescription. ${ }^{5,6}$ Previous studies have shown high rates of self medication (35\%) amongst medical students with respect to antibiotics. $^{7}$

Another study has reported that more than $60 \%$ of the participants believed that antibiotics should be prescribed for viral illnesses. ${ }^{8}$ Such wrong beliefs may lead to inappropriately high rates of antibiotic consumption, which can result in a corresponding increase in the bacterial resistance.

Such studies among Indian medical students are very few. A smaller study done among $862^{\text {nd }}$ year MBBS students in Nagpur showed that $94 \%$ of the respondents were aware that bacteria were not responsible for causing colds and flu. ${ }^{9}$

In this study we aim to know awareness and practice about antimicrobial use and resistance among medical students of different years so that appropriate measures can be taken to educate them properly to prevent misuse of antimicrobial as far as possible.

\section{Objectives}

1. Assessment of knowledge, attitude, practice about antimicrobial use and resistance among undergraduate medical students of different years by questionnaire-based survey.

2. Whether the knowledge on antimicrobial practice is improving with acquiring knowledge in different years of MBBS.

3. Emphasization for need for regular education for the students to prevent misuse of antimicrobials

\section{METHODS}

This study is a cross-sectional, questionnaire-based survey which is undertaken in a teaching hospital in Eastern India to be conducted between February 2017 and March 2017. The questionnaire was developed by modifying the earlier ones which were used. ${ }^{10,11}$ The questionnaire was validated by subject experts for its content and relevance.

The questionnaire was distributed among 328 medical students in their second, fourth, sixth and eighth semester of MBBS, at the end of their lecture classes.

The Institutional Ethics Committee permission was taken prior to initiation of the study. Each participant was allotted 20 minutes to answer the questionnaire in the form of options which he/she feels is appropriate to answer. They were asked to complete the questionnaire anonymously so that their responses remained confidential. Informed consents were obtained from the participants, to utilize their data for research purposes.
Total 328 students of 4 different years of MBBS of that medical college participated and submitted their responses in the questionnaire.

- The questions in the first part of the questionnaire assessed the students' knowledge about antibiotic resistance and usage. The participants' knowledge was assessed by using a set of true and false response questions.

The second part of the questionnaire addressed questions related to use of antimicrobials. These questions were intended to study the attitude of the participants regarding antibiotic resistance and usage. They were analyzed by options "agree" and "disagree".

- The third part of the questionnaire addressed questions related to their self reported practices regarding antibiotic usage. They were assessed by using options "always", "sometimes" and "never".

After getting their responses, total correct and incorrect responses from each participants were calculated and then, total correct and incorrect responses from that batch was calculated. In this process, we calculated total correct and incorrect responses from each of the 4 batches of MBBS students. Neutral answers were not added.

The analyze the response, Pearson's chi square test was done by SPSS version 22 to know the overall trend and also to assess batch wise difference in the responses, thus to have idea whether knowledge on antimicrobial practice is improving with acquiring knowledge in different years of MBBS.

\section{RESULTS}

Responses from 328 students were obtained for analysis.

Majority of the students agreed that indiscriminate antimicrobial use leads to the emergence of the growing problem of resistance and if they are taken too often, antimicrobials are less likely to work in the future. Also majority of the students know that bacteria do not cause common cold and influenza. Also majority of them agreed that antibiotic Resistance is an important and serious global public health issue and ineffective treatment can occur due to indiscriminate and injudicious antimicrobial use.

In the question whether antimicrobials are safe drugs and whether they can be commonly used, response were divided. 152 students (46.34\%) disagreed and 142 students agreed in this matter. Whether skipping one or two doses does not contribute to the development of antibiotic resistance, 177 students $(53.96 \%)$ disagreed and only 117 students agreed correctly $(35.67 \%)$. Response was again divided equally when they were asked whether adverse effects of antimicrobials are reduced by using more than 
one antimicrobial at a time. 134 students $(40.85 \%)$ agreed but 124 students disagreed correctly.

Majority of them correctly disagreed that injudicious use of antimicrobials shortens the duration of illness. But when asked that whether antibiotics should be used as first line drug in common cold, though 139 students disagreed correctly, 132 students agreed in that.

When asked what to do when after taking 2-3 doses of doctor prescribed antibiotic, if they started feeling better, majority don't stop taking the further treatment and they don't save the remaining antibiotics for the next time they get sick. But majority of them do not discard the remaining, leftover medication, also majority of them do not give the leftover antibiotics to their friend/roommate if they get sick. Majority agreed that they complete the full course of treatment?

Majority of them told that they consult a doctor before starting an antibiotic and also they check the expiry date of the antibiotic before using it. But majority of them are preferring to take an antibiotic when they have cough and sore throat.

When asked about the solution for the growing problem of Antimicrobial Resistance, only 173 students correctly have some idea about preventing it by judicious use, by taking antibiotics as per physicians' advice, not to use drugs in common viral illness. Rest of the students have no idea or wrong idea to tackle this problem.

Analysis of overall trend for correct and incorrect responses was done by Pearson's chi-square test and the chi-square value obtained was 18.55 with degree of freedom 3 and $p$ value $<0.001$, which is very significant and showed that students of this college gave correct responses in most of the questions.

Now, while assessing any difference in different batches, again chi square tests were applied. Proportion of correct response: incorrect response was 2.84 in $2^{\text {nd }}$ semester students, 2.38 in $4^{\text {th }}$ semester students, 3.26 in $6^{\text {th }}$ semester students and 3.29 in $8^{\text {th }}$ semester students.

Table 1: Total correct and incorrect responses of all questions in different batches of MBBS students.

\begin{tabular}{|lllll|}
\hline Batches & Participants & $\begin{array}{l}\text { Correct } \\
\text { response } \\
\text { (total) }\end{array}$ & $\begin{array}{l}\text { incorrect } \\
\text { response } \\
\text { (total) }\end{array}$ & Proportion \\
\hline Semester & & & \\
\hline $2^{\text {nd }}$ & 98 & 1177 & 415 & 2.84 \\
\hline $4^{\text {th }}$ & 100 & 1143 & 480 & 2.38 \\
\hline $6^{\text {th }}$ & 84 & 1104 & 339 & 3.26 \\
\hline $8^{\text {th }}$ & 46 & 622 & 189 & 3.29 \\
\hline
\end{tabular}

Proportion of $2^{\text {nd }}$ and $4^{\text {th }}$ semester, $4^{\text {th }}$ and $6^{\text {th }}$ semester, $6^{\text {th }}$ and $8^{\text {th }}$ semester was analyzed by chi square test and the result is shown in the Table 2 .
Table 2: Difference in knowledge on antimicrobial use with progression of MBBS course.

\begin{tabular}{|llll|}
\hline $\begin{array}{l}\text { Analyzing between } \\
\mathbf{2} \text { batches }\end{array}$ & $\begin{array}{l}\text { Chi } \\
\text { square } \\
\text { value }\end{array}$ & $\begin{array}{l}\text { Degree } \\
\text { of } \\
\text { freedom }\end{array}$ & P value \\
\hline $2^{\text {nd }}$ and $4^{\text {th }}$ Semester & 4.92 & 1 & 0.027 \\
\hline $4^{\text {th }}$ and $6^{\text {th }}$ Semester & 14.43 & 1 & $<0.001$ \\
\hline $6^{\text {th }}$ and $8^{\text {th }}$ Semester & 0.01 & 1 & 0.92 \\
\hline
\end{tabular}

Table 2 shows that difference of response changed very significantly from $4^{\text {th }}$ semester to $6^{\text {th }}$ semester.

\section{DISCUSSION}

Responses from 328 students of 4 different batches of MBBS students showed that most of them had idea about problem of antimicrobial resistance and most of the students answered majority of the questions correctly.

Though in some questions, their lack of proper awareness is absent. For example, many students told that skipping 12 doses of antibiotic doesn't lead to development of resistance, which is not true. Also, many students agreed that adverse effect of one antimicrobial agent can be reduced by simultaneous use of another antimicrobial, which is not true also.

Another area which need to be corrected is that most of the students do not discard the leftover antimicrobials after the course/illness is completed, rather they tend to use those in future for their own illness or illness among friends without consulting senior physicians, which can lead to antimicrobial resistance in future.

While assessing difference in responses in different batches, result showed that there was very significant improvement in the response of $6^{\text {th }}$ semester students than the response of $4^{\text {th }}$ semester students. The possible explanation may be that during the end of 4 th semester and $5^{\text {th }}$ semester, MBBS students learn about antimicrobials in detail in their pharmacology classes, and to some extent in microbiology classes, thus they become more aware about the appropriate use of antimicrobials.

Though there is no significant change in responses of $6^{\text {th }}$ and $8^{\text {th }}$ semester students, which means their knowledge on antimicrobial use is not increasing much after $6^{\text {th }}$ semester. This can be achieved by taking regular CME (continuous medical education) and group discussions, printed handouts, Posters, etc can be used for giving information for better understanding of the problem so that the area where there are still lacunae are present, those can be improved before they start practising as MBBS doctors.

Earlier study on antimicrobial use among physicians of the same institute where this study was done, that identified topics to address in the containment of antimicrobials resistance, such as the dissemination of information about 
local antimicrobial resistance rates, the importance of renewing public confidence in the quality of locally available antimicrobials, the revision and dissemination of local guidelines, and most importantly emphasization on regular educational activities among physicians regarding appropriate use of antimicrobials. ${ }^{12}$

Antibiotic knowledge need to be incorporated from the beginning period of MBBS so that with repeated learning, they become well aware of the problem and thus act appropriately to prevent antimicrobial resistance further.

Similar kinds of survey need to be done on multicentric basis to have proper steps to increase antimicrobial awareness among MBBS students.

\section{CONCLUSION}

Overall knowledge of antimicrobial resistance and proper use of antimicrobials appears good among different batches of MBBS student of this institution, though some areas need to be improved by continuous education.

Knowledge improvement is most evident from $4^{\text {th }}$ semester to $6^{\text {th }}$ semester students, most probably due to their learning about antimicrobials in detail in pharmacology classes in $4^{\text {th }}$ and $5^{\text {th }}$ semester. So pharmacology learning helped to grow antimicrobial awareness among students. Though it was expected that $8^{\text {th }}$ semester student would have better knowledge than $6^{\text {th }}$ semester students, it was not so, and for that students need to do group discussions, more practical case-oriented learning to have adequate knowledge regarding prevention of antimicrobial resistance before completion of MBBS course.

Funding: No funding sources

Conflict of interest: None declared

Ethical approval: The study was approved by the Institutional Ethics Committee

\section{REFERENCES}

1. Tripathi KD. Antimicrobial drugs-General Considerations, Essentials of Medical Pharmacology, $7^{\text {th }}$ Edition, Jaypee, Chapter 49; 2013:688-866.

2. Gumbo T, General Principles of antimicrobial therapy, Goodman and Gilman's The Pharmacological Basis of Therapeutics, $12^{\text {th }}$ Edition, Mc Graw Hill, Chap 48; 2010:1376.
3. Cars O, Nordberg P. Antibiotic resistance. The faceless threat. Int J Risk Saf Med. 2005;17:103-10.

4. Grigoryan L, Burgerhof JG, Haaijer-Ruskamp FM, Degener JE, Deschepper R, Monnet DL, et al. Is selfmedication with antibiotics in Europe driven by prescribed use? J Antimicrob Chemother. 2007:59:152-6.

5. Rathnakar UP, Sharma NK, Garg R, Unnikrishnan B, Gopalakrishna HN. A study on the sale of antimicrobial agents without prescriptions in pharmacies in an urban area in South India. J Clin Diagn Res. 2012;6:951-4.

6. Saradamma RD, Higginbotham N, Nichter M. Social factors influencing the acquisition of antibiotics without prescription in Kerala State, South India. Soc Sci Med. 2000;50:891-903.

7. Azevedo MM, Pinheiro C, Yaphe J, Baltazar F. Portuguese students, knowledge of antibiotics: a crosssectional study of secondary school and university students in Braga. BMC Public Health. 2009;9:359.

8. Zafar SN. Self-medication amongst university students of Karachi: Prevalence, knowledge and attitudes. JPMA. 2008;58:214-7.

9. Mahajan M, Dudhgaonkar S, Deshmukh S. A Questionnaire based Survey on the Knowledge, Attitude and Practises about Antimicrobial Resistance and Usage among the Second year MBBS Students of a Teaching tertiary care Hospital in Central India. International Journal of Pharmacological Research, 2014;4(4):175-9.

10. Wester CW, Durairaj L, Evans AT, Schwartz DN, Husain S, Martinez E. Antibiotic Resistance. A Survey of Physician Perceptions. Arch Intern Med. 2002;162:2210-16.

11. Eng JV. Consumer attitudes and use of antibiotics. Emerging Infectious Diseases. September. 2003;9(9):1128-35.

12. Ghosh A, Deb T, Ghosh S. Knowledge, attitudes and practice survey about antimicrobial resistance and prescribing among physicians in a tertiary care teaching hospital in Eastern India. Int J Basic Clin Pharmacol. 2016;5:180-7.

Cite this article as: Ghosh A, Das S, Dasgupta R.

Knowledge, attitude and practices about antimicrobial resistance and appropriate use of antimicrobial agents among the MBBS students of a medical college hospital in Eastern India. Int J Basic Clin Pharmacol 2018;7:370-4. 


\section{ANNEXURE}

Questionnaire

Semester- age- sex:

\section{Reply with True or false or uncertain:}

1.) Indiscriminate antimicrobial use leads to the emergence of the growing problem of resistance-.

2.) Antimicrobial resistance means that if they are taken too often, antimicrobials are less likely to work in the future-

3.) Bacteria cause common cold and influenza-

4.) Antibiotic Resistance is an important and serious global public health issue-

5.) Ineffective treatment can occur due to indiscriminate and injudicious antimicrobial use-

\section{Reply with: agree, undecided, disagree:}

6.) Antibiotics are safe drugs; hence they can be commonly used medication

7.) Skipping one or two doses does not contribute to the development of antibiotic resistance.

8.) Adverse effects of antimicrobials are reduced by using more than one antimicrobial at a time-.

9.) Injudicious use of antimicrobials shortens the duration of illness-

10.) When you have a cough and sore throat, antimicrobials are the first drug of choice for early treatment and to prevent emergence of resistant strains-

\section{Reply with always, sometimes, never:}

11.) The Doctor prescribes a course of antibiotic for you. After taking 2-3 doses you start feeling better.

a) Do you stop taking the further treatment?

b) Do you save the remaining antibiotics for the next time you get sick?

c) Do you discard the remaining, leftover medication?

d) Do you give the leftover antibiotics to your friend/roommate if they get sick?

e) Do you complete the full course of treatment?

12.) Do you consult a doctor before starting an antibiotic?

13.) Do you check the expiry date of the antibiotic before using it?

14.) Do you prefer to take an antibiotic when you have cough and sore throat?

\section{An idea on how to address problem of antimicrobial resistance:}

15.) What according to you is the solution for the growing problem of Antimicrobial Resistance? 